J. Clin. Chem. Clin. Biochem.

Vol. 20, 1982, pp. 25-28

\title{
Some Aspects of the Circadian Rhythm of the Urinary Excretion of Etiocholanolone, Androsterone and Dehydroepiandrosterone
}

\author{
By Eveline J. G. M. van Voorst tot Voorst \\ Department of Clinical Chemistry, Onze Lieve Vrouwe Gasthuis, Amsterdam, The Netherlands
}

(Received December 11, 1980/July 22, 1981)

Summary: The circadian rhy thm in the urinary excretion of etiocholanolone, of androsterone and of dehydroepiandrosterone in normal menstruating women was studied.

The excretion patterns of etiocholanolone and androsterone seem to be nearly synchronous, but not equal, thus resulting in a diurnal variation.

\section{Einige Aspekte des circadianen Rhythmus der Ausscheidung von Etiocholanolon, Androsteron und Dehydroepiandrosteron im Harn}

Zusammenfassung: Der circadiane Rhythmus in der Ausscheidung von Etiocholanolon, Androsteron und Dehydroepiandrosteron im Harn normal menstruierender Frauen wurde untersucht.

Die Ausscheidungsmuster von Etiocholanolon und Androsteron scheinen nahezu synchron zu sein, aber nicht gleich und zeigen somit eine diurnale Variation.

\section{Introduction}

It is known that the urinary excretion of 17-oxosteroids occurs in a circadian rhythm (1). Since dehydroepiandrosterone ${ }^{1}$ ), etiocholanolone and androsterone are quantitatively the most important 17 -oxosteroids, it is obvious to suppose that this rhythm is caused by one or more of them. In the case of the latter the question arises whether the circadian rhythm is parallel for each steroid, or whether the relative proportions of the excretion pattern vary during 24 hours. This may be of importance since in several publications the etiocholanolone/androsterone ratio, calculated from the urinary steroid excretion pattern, is mentioned as parameter separate from other parameters for some pathological syndromes. The etiocholanolone/androsterone ratio is increased in patients with Cushing's syndrome (2), and in $5 \alpha$-reductase deficiency (3); it is decreased in patients with hyperthyreoidism $(4,2)$, in the Stein Leventhal syndrome $(5,6)$, and in adrenoblastome (7). Keutmann (4) considers an etiocholanolone/androsterone ratio of about 1.0 as normal for woman at age 20 years, and he finds that the ratio slowly increases with age. Moolenaar

\footnotetext{
1) Trivial names used and their systematic equivalents are: dehydroepiandrosterone, $3 \beta$-hydroxy- $\Delta^{5}$-androsten-17-one; etiocholanolone, $3 \alpha$-hydroxy-5 $\beta$-androstan-17-one; androsterone, $3 \alpha$-hydroxy-5 $\alpha$-androstan-17-one; cholestanone, $5 \alpha$-cholestan-3-one; pregnanediol, $5 \beta$-pregnane-3 $\alpha, 20 \alpha$-diol
}

(2) reports a reference value of $0.90 \pm 0.22$ (mean \pm $\mathrm{SD}$ ) for normal women in the age range $19-44$ years. In our laboratory we found etiocholanolone/androsterone ratios between 0.7 and 1.3 ( $\pm 2 \mathrm{SD}$ ); these were calculated from the urinary steroid excretion pattern, obtained by the method of Van Kampen (8).

This publication describes our investigation on the existence of a diurnal variation of the urinary excretion of etiocholanolone, androsterone and dehydroepiandrosterone, and the interrelationship of these rhythms. For this purpose the steroid excretion patterns in the urine of 8 normal women, aged between 20 and 37 years. were analysed. The urine was collected in portions of 8 hours covering 24 hours. Urine collection was monitored by the determination ( 9 ) of urinary creatinine.

\section{Materials and Methods}

Materials

Eight normal female volunteers in the age range 20-37 years participated in this investigation. They made know that they either never used oral contraceptives or had stopped the intake of them at least three months bofore the beginning of the tests. During two days in the follicular phase and during two days in the luteal phase of the menstrual cycle they collected their urine. This was done in 8 hour samples (I: 07.00-15.00 h, II: $15.00-23.00 \mathrm{~h}$, Ill: $23.00-07.00 \mathrm{~h}$ ). From each of these samples a part in proportion to the volume was taken and mixed to give sample IV $(07.00-07.00 \mathrm{~h})$. The urines were kept at $4^{\circ} \mathrm{C}$ until analysis, which was performed within 1 week. Samples I, II, III and IV of one volunteer were analysed in one series. 
Methods

The urinary steroid excretion patterns were determined in two way's:

1) The acidic hydrolysis was performed as described by Rubens (6). This comprised two hydrolyses in different acidic media.

a) The hydrolysis of urinary steroid esters is accomplished in a strong acidic medium (earlier described by Van Kampen (8)). Steroids thus liberated are extracted from the aqueous phase by 1,2-dichloroethane simultaneously present in the reaction tube. The dichlorocthane phase is separated from the aqueous phase and washed with demineralized water. The dichloroethane is evaporated. The extract of the steroids is dissolved in an ethanolic solution of cholestanone $\left.{ }^{1}\right)(40 \mathrm{mg} / \mathrm{l}$, internal standard). The gas liquid chromatography separation was performed with a Hewlett-Packard 5750 instrument equipped with a flame ionization detector and with two glass columns, packed with $3.8 \%$ SE 30 on chromosorb W-AW-DMCS (80-100 mesh). The temperature of the columns is programmed $\left(200-250^{\circ} \mathrm{C}\right)$. Chromatograms obtained by this method show two dominant peaks, representing etiocholanolone and androsterone plus dehydroepiandrosterone, and a peak of cholestanone. The areas of these peaks are calculated.

The contents of etiocholanolone and androsterone plus dehydroepiandrosterone are derived by comparing these areas.

b) A second urine sample was hydrolyzed in a weakly acidic medium (pH: 4.7) in such a manner that only dehydroepiandrosteronc sulphate was hydrolyzed as earlier described by Jayle (10). After the hydrolysis dehydroepiandrosterone was extracted by 1,2-dichloroethane. The dichloroethane phase ivas separated from the aqueous phase and washed with demineralized water. The dichloroethane was evaporated. The extract of dehydroepiandrosterone was treated in the same way as described under a. By subtracting the content of dehydroepiandrosterone from the sum of androsterone plus dehydroepiandrosterone the content of androsterone may be calculated.

The within-run precision for etiocholanolone is $5.2 \%$, for androsterone and dehydroepiandrosterone $4 \%$ and for dehydroepiandrosterone (method b) $3.9 \%$.

The between day precision for etiocholanolone is $6.9 \%$, for androsterone and dehydroepiandrosterone $6.0 \%$ and for dehydroepiandrosterone $5 \%$.

Although not investigated extensively, the good correlation between the methods mentioned under 1 and 2 indicates that the methods are accurate.

2) The enzy matic hydrolysis and solvolysis of the steroid esters were performed according to Burstein (11). The extraction, the preparation and the gas liquid chromatographic separation of the trimethylsilyl ethers of the steroids were performed as described by Moolenaar (2).

The creatinine content of the urinary portions was determined by continuous flow analysis by means of the reaction of Jaffé (12). The within-variability of this method is $2 \%$.

The ovulation in the menstrual cycle was checked by measuring the basal tempcrature of the volunteers. Since pregnanediol ${ }^{1}$ ) is also measured in the steroid excretion pattern by the above described method 1), the ovulation could also be established by the increase of pregnanediol.

The data were evaluated statistically by the Wilcoxon's test (13).

\section{Results}

All female volunteers had a biphasic basal temperature curve. Also the rise of the pregnanediol content of the urine in the luteal phase showed that the ovulation had occurred.

In table 1 the results of the creatinine excretions are given, in particular the number, the range and the mean of the excretions in the follicular phase and in the luteal phase.

In table 2 the results of the excretion of etiocholanolone, of androsterone and of dehydroepiandrosterone are given, in particular the number, the range and the mean of the excretions in the follicular and luteal phase.

The range, mean and the number of analyses of the etiocholanolone/androsterone ratio of the urinary samples in the follicular and in the luteal phase are given in table 3 .

The results mentioned in table 2 and 3 are obtained with the acidic hydrolysis. In table 4 the results of the enzymatic hydrolysis (method 2) are given. These urinary portions are from two women, 3 portions in the follicular phase and 3 in the luteal phase of the menstrual cycle.

\section{Discussion}

The creatinine excretion (table 1) is slightly but significantly $(\mathrm{P}<0.01)$ greater in the luteal phase than in the follicular phase of the menstrual cycle. Also is found that the creatinine excretion in sample II (15.00$23.00 \mathrm{~h}$ ) is higher than the excretion in samples I $(\mathrm{P}<0.02)$ and III $(\mathrm{P}<0.01)$. There is no significant difference in the excretion in samples I and III $(P>0.1)$.

The results of etiocholanolone and dehydroepiandrosterone excretions (table 2) show nó démonstrable differences $(\mathrm{P}>0.10$ and $\mathrm{P}>0.10$ respectively) in excretion in the follicular phase and in the luteal phase. The excretion of androsterone is slightly but significantly $(\mathrm{P}<0.02)$ higher in the luteal phase than in the follicular phase. There is an indication that the excretion of etiocholanolone, of androsterone and of dehydroepiandrosterone occurs in a circadian rhythm. The excretion of etiocholanolone and of androsterone in sample I $(07.00-15.00 \mathrm{~h})$ is significantly higher $(\mathrm{P}<0.01)$ than in sample II, the latter being significantly higher $(\mathrm{P}<0.01)$ than in sample III. The excretion of de-

Tab. 1. The number, the range and the mean of creatinine excretion (absolute values) in the follicular and in the luteal phase.

\begin{tabular}{|c|c|c|c|c|c|c|}
\hline \multirow[t]{2}{*}{ Sample } & \multicolumn{3}{|c|}{ Follicular phase } & \multicolumn{3}{|c|}{ Luteal phase } \\
\hline & $\mathrm{n}$ & $\begin{array}{l}\text { Range } \\
\text { (mmol) }\end{array}$ & $\begin{array}{l}\text { Mean } \\
\text { (mmol) }\end{array}$ & $n$ & $\begin{array}{l}\text { Range } \\
\text { (mmol) }\end{array}$ & $\begin{array}{l}\text { Mean } \\
\text { (mimol) }\end{array}$ \\
\hline $\begin{array}{r}\text { I }(07.00-15.00 \mathrm{~h}) \\
\text { II }(15.00-23.00 \mathrm{~h}) \\
\text { III }(23.00-07.00 \mathrm{~h}) \\
\text { IV }(07.00-07.00 \mathrm{~h}) \\
\end{array}$ & $\begin{array}{l}16 \\
16 \\
16 \\
16\end{array}$ & $\begin{array}{l}3.0-4.9 \\
2.7-5.4 \\
2.8-4.5 \\
8.4-14.3\end{array}$ & $\begin{array}{r}3.8 \\
4.0 \\
3.6 \\
11.3\end{array}$ & $\begin{array}{l}15 \\
15 \\
15 \\
15\end{array}$ & $\begin{array}{l}3.0^{\circ}-5.3 \\
3.0-7.2 \\
3.0-6.9 \\
8.8-19.4\end{array}$ & $\begin{array}{r}3.9 \\
4.5 \\
4.1 \\
12.4\end{array}$ \\
\hline
\end{tabular}


Tab. 2. The number, the range and the mean of the excretion of etiocholanolone, androsterone and dehydroepiandrosterone (absolute values) in the follicular and lutcal phase.

\begin{tabular}{|c|c|c|c|c|c|c|c|c|c|c|}
\hline \multirow{2}{*}{$\begin{array}{l}\text { Phase of } \\
\text { menstrual } \\
\text { cycle }\end{array}$} & \multirow[t]{2}{*}{ Sample } & \multicolumn{3}{|c|}{ Etiocholanolone } & \multicolumn{3}{|c|}{ Androsterone } & \multicolumn{3}{|c|}{ Dehydrocpiandrosterone } \\
\hline & & $\mathrm{n}$ & $\begin{array}{l}\text { Range } \\
\text { ( } \mu \mathrm{mol})\end{array}$ & $\begin{array}{l}\text { Mean } \\
(\mu \mathrm{mol})\end{array}$ & $\mathrm{n}$ & $\begin{array}{l}\text { Range } \\
(\mu \mathrm{mol})\end{array}$ & $\begin{array}{l}\text { Mean } \\
(\mu \mathrm{mol})\end{array}$ & $\mathrm{n}$ & $\begin{array}{l}\text { Range } \\
(\mu \mathrm{mol})\end{array}$ & $\begin{array}{l}\text { Mean } \\
(\mu \mathrm{mol})\end{array}$ \\
\hline Follicular & $\begin{array}{l}\text { I } \\
\text { II } \\
\text { III } \\
\text { IV }\end{array}$ & $\begin{array}{l}16 \\
16 \\
16 \\
16\end{array}$ & $\begin{array}{l}2.55-8.60 \\
1.80-8.15 \\
1.40-5.30 \\
5.50-19.90\end{array}$ & $\begin{array}{r}5.35 \\
4.45 \\
3.45 \\
12.85\end{array}$ & $\begin{array}{l}16 \\
16 \\
16 \\
16\end{array}$ & $\begin{array}{l}2.20-8.30 \\
2.15-8.70 \\
1.60-5.30 \\
5.90-21.55\end{array}$ & $\begin{array}{r}4.85 \\
4.25 \\
3.00 \\
11.85\end{array}$ & $\begin{array}{l}16 \\
16 \\
16 \\
16\end{array}$ & $\begin{array}{l}0.05-3.45 \\
0.05-3.90 \\
0.00-1.95 \\
0.10-9.20\end{array}$ & $\begin{array}{l}0.95 \\
0.90 \\
0.35 \\
2.15\end{array}$ \\
\hline Luteal & $\begin{array}{l}\text { I } \\
\text { II } \\
\text { III } \\
\text { IV }\end{array}$ & $\begin{array}{l}15 \\
15 \\
15 \\
15\end{array}$ & $\begin{array}{l}3.30-8.05 \\
3.10-6.95 \\
2.15-6.05 \\
9.10-19.50\end{array}$ & $\begin{array}{r}5.30 \\
4.40 \\
3.60 \\
12.80\end{array}$ & $\begin{array}{l}15 \\
15 \\
15 \\
15\end{array}$ & $\begin{array}{l}2.70-9.95 \\
1.85-7.85 \\
1.50-6.90 \\
6.60-23.00\end{array}$ & $\begin{array}{r}5.30 \\
4.65 \\
3.40 \\
13.05\end{array}$ & $\begin{array}{l}15 \\
15 \\
15 \\
15\end{array}$ & $\begin{array}{l}0.05-4.15 \\
0.05-5.50 \\
0.00-5.20 \\
0.10-12.50\end{array}$ & $\begin{array}{l}0.85 \\
1.10 \\
0.75 \\
2.60\end{array}$ \\
\hline
\end{tabular}

Tab. 3. All values of the etiocholanolone/androsterone ratio ( $\mu \mathrm{mol} / \mu \mathrm{mol}$ ) of the 8-hour urinary samples.

\begin{tabular}{|c|c|c|c|c|c|c|c|}
\hline \multicolumn{8}{|c|}{ Etiocholanolone/androsterone ratio } \\
\hline \multirow{2}{*}{$\begin{array}{l}\text { Per- } \\
\text { son }\end{array}$} & \multirow{2}{*}{$\begin{array}{l}\text { Sam- } \\
\text { ple }\end{array}$} & \multicolumn{3}{|c|}{ Follicular phase } & \multicolumn{3}{|c|}{ Luteal phase } \\
\hline & & Day 1 & Day 2 & Mean & Day 1 & Day 2 & Mean \\
\hline$a$ & $\begin{array}{l}\text { I } \\
\text { II } \\
\text { III }\end{array}$ & $\begin{array}{l}0.84 \\
0.91 \\
0.78\end{array}$ & $\begin{array}{l}1.05 \\
0.87 \\
1.00\end{array}$ & $\begin{array}{l}0.94 \\
0.89 \\
0.89\end{array}$ & $\begin{array}{l}0.70 \\
0.75 \\
0.79\end{array}$ & $\begin{array}{l}0.85 \\
0.78 \\
0.96\end{array}$ & $\begin{array}{l}0.78 \\
0.76 \\
0.88\end{array}$ \\
\hline b & $\begin{array}{l}\text { I } \\
\text { II } \\
\text { III }\end{array}$ & $\begin{array}{l}0.78 \\
0.68 \\
0.85\end{array}$ & $\begin{array}{l}0.80 \\
0.72 \\
0.82\end{array}$ & $\begin{array}{l}0.7 \\
0.7 \\
0.8\end{array}$ & $\begin{array}{l}0.66 \\
0.55 \\
0.64\end{array}$ & $\begin{array}{l}0.67 \\
0.58 \\
0.71\end{array}$ & $\begin{array}{l}0.66 \\
0.56 \\
0.68\end{array}$ \\
\hline c & $\begin{array}{l}\text { I } \\
\text { II } \\
\text { III }\end{array}$ & $\begin{array}{l}0.97 \\
0.85 \\
0.87\end{array}$ & $\begin{array}{l}1.23 \\
1.02 \\
1.22\end{array}$ & $\begin{array}{l}1.1 \\
0.9 \\
1.0\end{array}$ & $\begin{array}{l}1.24 \\
1.05 \\
1.21\end{array}$ & $\begin{array}{l}1.30 \\
1.20 \\
1.20\end{array}$ & $\begin{array}{l}1.27 \\
1.12 \\
1.20\end{array}$ \\
\hline d & $\begin{array}{l}\text { I } \\
\text { II } \\
\text { III }\end{array}$ & $\begin{array}{l}2.10 \\
2.03 \\
2.21\end{array}$ & $\begin{array}{l}2.05 \\
2.09 \\
1.97\end{array}$ & $\begin{array}{l}2.0 \\
2.0 \\
2.0\end{array}$ & $\begin{array}{l}1.92 \\
1.89 \\
1.88\end{array}$ & $\begin{array}{l}1.92 \\
1.92 \\
1.74\end{array}$ & $\begin{array}{l}1.92 \\
1.90 \\
1.81\end{array}$ \\
\hline e & $\begin{array}{l}\text { I } \\
\text { II } \\
\text { III }\end{array}$ & $\begin{array}{l}1.08 \\
0.94 \\
1.01\end{array}$ & $\begin{array}{l}1.02 \\
0.98 \\
0.96\end{array}$ & $\begin{array}{l}1.05 \\
0.96 \\
0.98\end{array}$ & $\begin{array}{l}0.95 \\
0.81 \\
0.92\end{array}$ & $\begin{array}{l}0.78 \\
0.89 \\
0.87\end{array}$ & $\begin{array}{l}0.86 \\
0.85 \\
0.90\end{array}$ \\
\hline f & $\begin{array}{l}\text { I } \\
\text { II } \\
\text { III }\end{array}$ & $\begin{array}{l}1.10 \\
1.15 \\
1.49\end{array}$ & $\begin{array}{l}1.21 \\
1.28 \\
1.33\end{array}$ & $\begin{array}{l}1.16 \\
1.22 \\
1.41\end{array}$ & $\begin{array}{l}1.19 \\
1.25 \\
1.26\end{array}$ & $\begin{array}{l}x \\
x \\
x\end{array}$ & $\begin{array}{l}1.19 \\
1.25 \\
1.26\end{array}$ \\
\hline g & $\begin{array}{l}\text { I } \\
\text { II } \\
\text { III }\end{array}$ & $\begin{array}{l}1.01 \\
1.01 \\
1.01\end{array}$ & $\begin{array}{l}1.00 \\
0.96 \\
1.00\end{array}$ & $\begin{array}{l}1.00 \\
0.98 \\
1.00\end{array}$ & $\begin{array}{l}0.84 \\
0.94 \\
1.05\end{array}$ & $\begin{array}{l}0.86 \\
0.78 \\
0.94\end{array}$ & $\begin{array}{l}0.85 \\
0.86 \\
1.00\end{array}$ \\
\hline h & $\begin{array}{l}\text { I } \\
\text { II } \\
\text { III }\end{array}$ & $\begin{array}{l}1.41 \\
1.31 \\
1.35\end{array}$ & $\begin{array}{l}1.40 \\
1.34 \\
1.40\end{array}$ & $\begin{array}{l}1.40 \\
1.32 \\
1.38\end{array}$ & $\begin{array}{l}1.29 \\
1.13 \\
1.42\end{array}$ & $\begin{array}{l}1.29 \\
1.32 \\
1.39\end{array}$ & $\begin{array}{l}1.29 \\
1.22 \\
1.40\end{array}$ \\
\hline
\end{tabular}

$x=$ These urinary samples were not collected.

hydroepiandrosterone in sample $I$ is not significantly different $(P>0.10)$ from the excretion in sample II.

The latter, however, is significantly higher $(P<0.01)$ than the excretion in sample III. The observed variation does not correspond to the observed variation in the excretion of creatinine.

The differences between the etiocholanolone/androsterone ratios of the urinary samples, collected during two days in the follicular phase are not significant $(P>0.1)$; the same true in the luteal phase $(P>0.1)$ (table 3 ). There is a small but significant difference
Tab. 4. Absolute values for the excretion of etiocholanolone, androsterone and dehydroepiandrosterone, and the etiocholanolone/androstcrone ratio of 3 urinary samples in the follicular phase and of 3 urinary samples in the luteal phase, determined by enzymatic hydrolysis (method 2).

\begin{tabular}{llllll}
\hline $\begin{array}{l}\text { Phase of } \\
\text { menstrual } \\
\text { cycle }\end{array}$ & Samplc & $\begin{array}{l}\text { Etiocho- Andro- } \\
\text { lanolone }\end{array}$ & $\begin{array}{l}\text { De- } \\
\text { sterone } \\
\text { hydro- } \\
\text { cpian- } \\
\text { droste- } \\
\text { ronc } \\
(\mu \mathrm{mol})\end{array}$ & $\begin{array}{l}\text { Etiochol- } \\
\text { anolone/ } \\
\text { andro- } \\
\text { steronc } \\
\text { ratio }\end{array}$ \\
\hline Follic- & I & 4.4 & 4.9 & 0.8 & 0.90 \\
ular & II & 3.2 & 3.9 & 0.5 & 0.82 \\
& III & 1.9 & 2.0 & 0.2 & 0.94 \\
Luteal & I & 4.7 & 5.4 & 0.3 & 0.87 \\
& II & 2.4 & 2.4 & 0.1 & 0.98 \\
& III & 2.0 & 1.8 & 0.1 & 1.13 \\
\hline
\end{tabular}

$(\mathrm{P}<0.05)$ between the etiocholanolone/androsterone ratios of the samples in the follicular and in the luteal phase.

The etiocholanolone/androsterone ratio of sample I is significantly higher $(\mathrm{P}<0.01)$ than the etiocholanolone/ androsterone ratio of sample II and the latter is significantly lower $(P<0.01)$ than sample III. Between the etiocholanolone/androsterone ratios of samples I and III there is no demonstrable difference $(P>0.10)$. Figure 1 shows clearly this rhythm of the etiocholanolone/androsterone ratio.

Dehydroepiandrosterone is the principal precursor of etiocholanolone and of androsterone. It is synthesized and secreted by the adrenal cortex and by the ovary (14).

The formation of etiocholanolone and androsterone occurs via androstenedione by reduction of the double bond between the rings $A$ and $B$. This reduction is catalyzed in the liver by the $\Delta^{4}$-steroid- $5 \beta$-reductase(s) localized in the cytosol and the $\Delta^{4}$-steroid- $5 \alpha$-reductase(s) of the membranes of the endoplasmic reticulum $(3,15)$. The synthesis and secretion by the adrenal cortex and the ovary are controlled by the pituitary by means of corticotropin and lutropin, follitropin respectively. The 


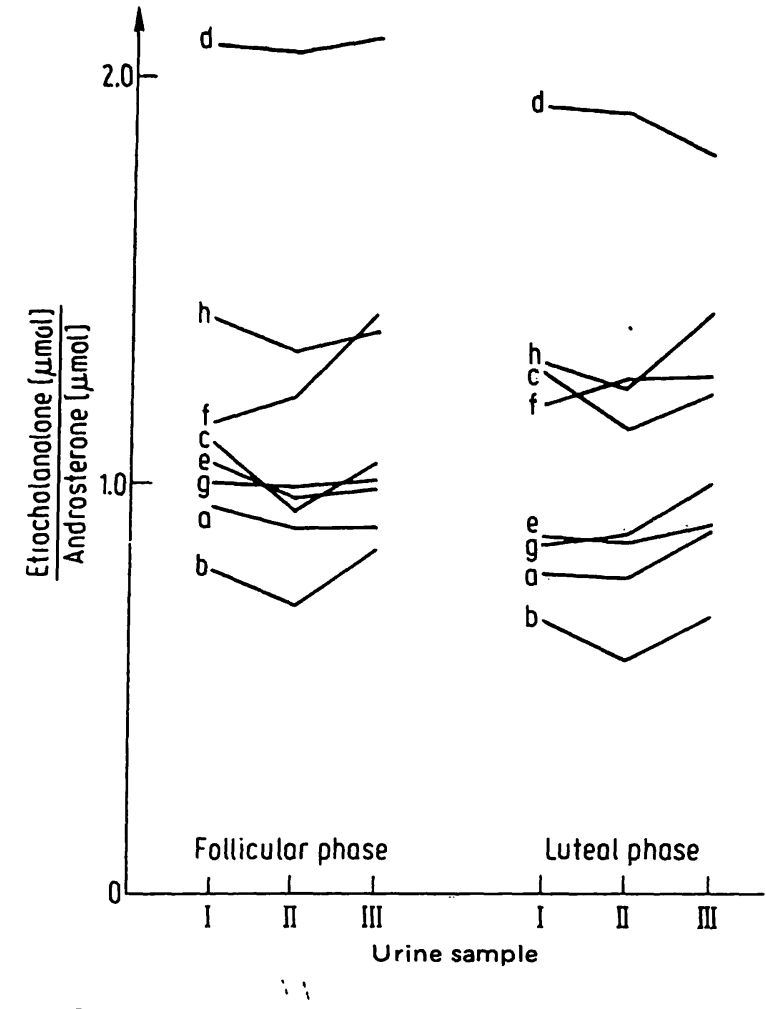

Fig. 1. From each of the eight volunteers $(a-h)$ the mean values of the etiocholanolone/androsterone ratio of the urinary samples in the follicular and in the luteal phase are shown.

observed variation in the excretion of etiocholanolone and androsterone can be explained by the demonstrated diurnal rhythm for corticotropin (16), and for lutropin and follitropin ((17), only 25 normal children aged 12 to 15 were involved in the investigation).

Our results indicate a greater excretion of androsterone in the luteal phase of the menstrual cycle. A higher level of androstenedione in the plasma in the post-ovulatory phase as compared with the pre-ovulatory phase has been described (18). The activity of the $\Delta^{4}-3-0 \times 0-C_{19}$ steroid-5 $\alpha$-reductase, present in the human ovary (19), might also be different in the two phases of the menstrual cycle. The observed variation in the etiocholanolone/androsterone ratio cannot be explained by the rhy thm of the pituitary hormones. One reason might be a possible difference in the reaction rate of the $5 \alpha$ reduction and the $5 \beta$-reduction in the liver. The $5 \alpha$ reductase in the hepatocyte is said to be stimulated by the thyroid hormones (2). Diurnal fluctuations in the thyroxine level of plasma are known (20). Another reason might be a diurnal variation of the activity of $5 \alpha$-reductase in the human ovary. In addition, there could be a difference in the rate of conjugation of etiocholanolone with glucuronic acid, and of androsterone with sulfuric and glucuronic acid, which are necessary for their excretion in urine.

\section{Acknowledgements}

We are very grateful to $\mathrm{Dr} . H$. Kruijswijk for this active interest and encouragement in this work, to Madeleine de Vries for her secretarial work, to our colleagues for their willingness to collect their urine, to Dr. A. J. Moolenaar and Mrs. L. van L̈eeuwen (Department of Chemical Pathology, University Hospital, Leiden) for their hospitality.

\section{References}

1. Bartter, F. C., Delea, C. S. \& Halberg, F. (1962) Ann. N.Y. Acad. Sci. 98, 969-983.

2. Moolenaar, A. J. \& Van Seters, A. P. (1971) Acta Endocrinol. (Copenhagen) 67, 303-315.

3. Imperato-McGinley, J., Guerrero, L., Gautier, T. \& Peterson, R. E. (1974) Science 186, 1213-1215.

4. Keutmann, E. H. \& Mason, W. B. (1967) J. Clin. Endocrinol. $27,406-420$.

5. Trocha, P. \& D'Amato, N. A. (1978) Clin. Chem. 24, 193199.

6. Rubens, M., (1976) Bepaling der 11-deoxy-17-ketosteroiden in urine, een gaschromatografisch onderzoek, Doctoral Thesis University of Amsterdam.

7. Cope, C. L. (1964) in Adrenal Steroids and Disease, Pitman Medical Publishing Company, London, 378.

8. Van Kampen, E. J. \& Anker, A. P. (1971) Clin. Chim. Acta $34,241-260$.

9. Gerritzen, F., Strengers, Th. \& Esser, S. (1969) Aerospace Medicine 40, 264-271.

10. Jayle, M. F. \& Malassis, D. (1958) Bull. Soc. Chim. Biol. 40 $1349-1373$ 11. Burstein, S. \& Lieberman, S. (1958) J. Biol. Chem. 233,
$331-335$.
12. Chasson, A. L., Grady, H. J. \& Stanley, M. A. (1961) Amer. J. Clin. Pathol. 35, 83-88.

13. Geigy, J. R. (1960) in Documenta Geigy Wissenschaftliche Tabellen, ed. 6, Basle, Switzerland, 170.23.

14. Nieschlag, E., Loriaux, D. L., Ruder, H. J., Zucker, I. R., Kirschner, M. A. \& Lipsett, M. B. (1973) J. End'ocrinol. 57, 123-134

15. Björkhem, I., Einarsson, K., Hellers, G. \& Wikvall, K. (1976) Acta Endocrinol. (Copenhagen) 81, 530-536.

16. Gallagher, T. F., Yoshida, K., Roffwarg, H. D., Fukushima, D. K., Weitzman, E. D. \& Hellman, L. (1973) J. Clin. Endocrinol. Metab. 36, 1058-1068.

17. Beck, W. \& Wuttke, W. (1980) J. Clin. Endocrinol. Metab. $50,635-639$.

18. Guerrero, R., Aso, T., Brenner, P. F., Cekan, Z., Landgren, B. M., Hagenfeldt, K. \& Diczfalusy, E. (1976) Acta Endo-' crinol. (Copenhagen) 81, 133-149.

19. Hillier, S. G., Van den Boogaard, A. M. J., Reichert, L. E. Jr. \& Van Hall, E. V. (1980) J. Clin. Endocrinol. Metab. 50, 640-647.

20. Daly, J. R. (1978) in Scientific Foundations of Clinical Biochemistry (Williams, D. L., Nunn, R. F. \& Marks, V. ed.) Vol I, 447, William Heinemann Books Limited, Londor.

Eveline J. G. M. van Voorst tot Voorst Department of Clinical Chemistry Żiekenhhuis de Weezenlanden NL-8011 JW Zwolle

J. Clin. Chem. Clin. Biochem. / Vol: 2̇o, 1982 / No. 1 